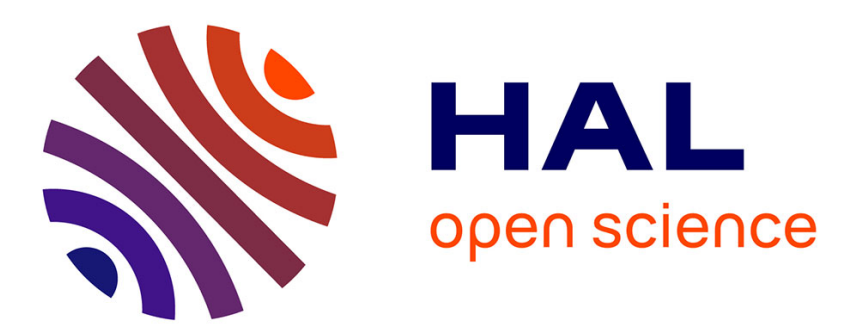

\title{
Response time of a canal pool for scheduled water delivery
}

\author{
Gilles Belaud, X. Litrico, A. Clemmens
}

\section{To cite this version:}

Gilles Belaud, X. Litrico, A. Clemmens. Response time of a canal pool for scheduled water delivery. Journal of Irrigation and Drainage Engineering, 2013, 139 (4), pp.300-308. 10.1061/(asce)ir.19434774.0000545 . hal-01111045

\section{HAL Id: hal-01111045 \\ https://hal.science/hal-01111045}

Submitted on 29 Jan 2015

HAL is a multi-disciplinary open access archive for the deposit and dissemination of scientific research documents, whether they are published or not. The documents may come from teaching and research institutions in France or abroad, or from public or private research centers.
L'archive ouverte pluridisciplinaire HAL, est destinée au dépôt et à la diffusion de documents scientifiques de niveau recherche, publiés ou non, émanant des établissements d'enseignement et de recherche français ou étrangers, des laboratoires publics ou privés. 


\title{
Response Time of a Canal Pool for Scheduled Water
}

\section{Delivery}

\author{
G. Belaud ${ }^{1}$, X. Litrico $^{2}$, A.J. Clemmens ${ }^{3}$
}

\begin{abstract}
Estimating the response time of a canal is essential for the open-loop control of an irrigation canal, since upstream flow releases must be anticipated in order to satisfy scheduled demands at irrigation outlets. We consider a flow release at the upstream end of a pool in order to satisfy a side withdrawal at its downstream end. When theflow is released, wave travel time causes the flow change to arrive some time later downstream and attenuation causes the flow to arrive gradually downstream, such that the peak discharge is further delayed. A clear definition of this response time is proposed, based on volume compensation. A linear approach is used to calculate the canal response to a flow release and a withdrawal, and then the volume passing at the downstream end of the canal. The approach provides an analytical determination of the time of opening that ensures volume compensation. A practical method to derive this response time is proposed. It is illustrated for a canal for which different downstream boundary conditions are imposed.
\end{abstract}

\section{Keywords: Response time, open-loop control, scheduled water delivery, flow propagation}

${ }^{1}$ UMR G-eau, SupAgro, 2, place Pierre Viala, 34060 Montpellier Cedex 5, France. Email : belaud@supagro.inra.fr

${ }^{2}$ LyRE, R\&D center, Lyonnaise des Eaux, Bordeaux, France, E-mail: xavier.litrico@lyonnaise-deseaux.fr

${ }^{3}$ West Consultants, 8950 South 52nd Street, Suite 210, Tempe, AZ 85284-1043, bclemmens@westconsultants.com 


\section{INTRODUCTION}

The timing of the delay in a canal with scheduled water deliveries is essential. If the scheduled water is released too early, excess water is lost, and if it is released too late, the delivery is not efficient. This timing is difficult to estimate because it may be influenced by the hydraulic condition of the canal. The backwater curve and the downstream boundary condition influence the time delay of a canal pool. These effects were illustrated by Strelkoff et al. (1998) through a simulation study of the influence of hydraulic structures on the delay of a canal pool. Several studies have attempted to define and calculate the response time of a pool [e.g.,Munier et al. (2010)]. Schuurmans (1990) proposed a method to calculate the time for downstream response to reach any proportion of the total increase, while other authors give a single value for this response time, based on maximum increase (Ankum, 1995) or dynamic storage (Schuurmans et al., 1995 ; Bautista et al., 2003). Munier et al. (2010) have proposed a method to compute the response time of a canal pool based on a first order with delay model that takes into account the backwater curve and the downstream boundary condition imposed by a hydraulic structure. However, this study chose to use the response time at $90 \%$, corresponding to the time when the discharge increase has reached $90 \%$ of its final value. This choice was rather arbitrary.

When the upstream flow is increased in order to deliver water to a lateral outlet, the discharge in the canal will decrease as soon as the outlet gate is opened. One may then try to find the proper time in order to deliver water to the outlet without affecting too much the flow in the canal. One way is to ensure that the total volume of water downstream from the gate remains constant. If the gate is opened too early, e.g. just as the wave arrives, more flow will be extracted than has arrived, and thus decreasing the amount of water available downstream. Conversely, if the outlet gate is opened too late, there will be an excess of flow in the main channel.

This paper uses the model developed by Munier et al. (2010) and the IDZ (Integrator Delay Zero) model developed by Litrico \& Fromion (2004) in order to find the appropriate time for the open-loop routing of demand changes. The results are then compared with a full 
Saint-Venant's equation solution for a test canal with different downstream boundary conditions. Finally,the concept of response time of an irrigation canal is discussed.

\section{THEORETICAL CONCEPTS}

The problem can be viewed as a superposition of two processes: the propagation of a flow release within a canal pool, and the decrease of the pool level when a side outlet is opened. Both processes are first analyzed separately, then they are combined to derive the time which ensures volume compensation. We consider a canal pool (Fig. ) supplied with a discharge $Q_{u}$. At a distance $L$ from the upstream head, an outlet may withdraw a discharge $Q_{w}$, while the remaining discharge is denoted $Q_{d}$. At that location, the flow may be in the backwater caused by an inline structure, or uniform if this structure is far enough. Two extreme situations will be considered. The first situation (Fig. 1, above), refered to as "uniform flow", is obtained by having a pool much longer than Lso that the level upstream of the outlet is not influenced by the pool downstream boundary condition. The second situation (Fig. 1, below) is when the outlet is located at the end of the pool, immediately upstream of a control structure. This control structure will be a gate or a weir.

$<$ Figure 1 about here $>$

\section{Propagation of a flow release}

Based on the linearization of the Saint-Venant equations, Munier et al. (2010) derived a simple first-order and delay (FOD) routing model, taking into account the effect of the downstream boundary condition. This model was then applied to actual field data, and was able to predict flow propagation very accurately. The temporal form of the transfer function may be written as :

$$
K \frac{d Q_{d}}{d t}(t)+Q_{d}(t)=Q_{u}(t-\tau)
$$


where $t$ is time, $\tau$ is the travel time of the wave from the upstream to downstream gate (primarily from celerity, but influenced by backwater), and $K$ represents the attenuation during the propagation. The parameters $K$ and $\tau$ may be calculated explicitly from the canal geometry and the flow conditions, including the effects of the downstream boundary condition. Alternatively, $K$ and $\tau$ may be identified from field data, with measured values of $Q_{u}(t)$ and $Q_{d}(t)$. The backwater curve affects both $\tau$ and $K$, but $K$ is also largely influenced by the sensitivity of the downstream discharge to water variations (feedback effect). This sensitivity is given by a feedback coefficient, denoted $k_{d}$, defined as :

$$
k_{d}=\left.\frac{\partial Q_{d}}{\partial Y}\right|_{Q_{0}}
$$

where $Y$ is the water depth, $Q_{0}$ is a reference discharge.

The scheduling problem consists of determining the time when to release a given discharge upstream, $\delta Q_{u}$, in order to supply the lateral outlet, located at the distance $L$, at a scheduled time. For a step discharge release at time $t=0$, and without lateral withdrawal, the deviation $q_{d}{ }^{(r)}$ of the downstream discharge $Q_{d}(t)$ from its initial value $Q_{0}$ is described by the closedform solution of Eq. (1), namely (Munier et al. 2010) :

- for $t<\tau$ :

$$
q_{d}^{(r)}(t)=q_{d, 0}=0
$$

- for $t \geq \tau$ :

$$
q_{d}^{(r)}(t)=\left(1-e^{-(t-\tau) / K}\right) \delta Q_{u}
$$

and, denoting yas the variation of $Y$ from its reference value $Y_{0}$ :

$$
y(t)=q_{d}^{(r)}(t) / k_{d}
$$

The subscript zero refers to the initial conditions. The delay time $\tau$ represents the time when the downstream discharge starts to increase. Equation 4 shows that the discharge change downstream raises gradually according to an exponential function. Field tests of this model are presented in Munier et al. (2010). 
We can also show that the expression $T=\tau+K$ represents the travel time of long waves, and that it should be close to the dynamic storage time $T_{V}=d V / d Q$ as defined by Burt and Plusquellec (1990). This time is sometimes used for irrigation scheduling but, to date, there is no proof that it ensures volume compensation. The propagation time of long waves is also a practical way to estimate $\tau+K$, and then $K$ if $\tau$ is assumed to be the travel time of the surface waves.

This time may also be compared to the propagation time $T_{d}$ of the diffusive wave. In an infinitely long uniform channel, the speed of the diffusive wave can be easily calculated from canal characteristics based on the continuity equation as :

$$
c_{d}=d Q / d A
$$

which gives, considering Manning’s equation and a rectangular channel,

$$
C_{d}=U_{0}\left(\frac{5}{3}-\frac{4}{3} \frac{Y_{n}}{b+2 Y_{n}}\right)
$$

where $U_{0}=\frac{1}{n} b Y_{n}\left(\frac{b Y_{n}}{b+2 Y_{n}}\right)^{2 / 3} \sqrt{S_{b}}$ is the mean velocity for discharge $Q$ in uniform flow, $A$ is the wetted area, $b$ is the canal width, $n$ is Manning roughness coefficient, $S_{b}$ the canal bed slope and $Y_{n}$ is the normal depth. According to Bautista et al. (2005), this time is an upper bound of the time which ensures volume compensation. The lower bound would be given by the speed of short waves, $C_{s w}=U_{0}+\sqrt{g D}$ ( $D$ is the hydraulic depth defined as the ratio of area to top width).Most canal pools are relatively short and have a shorter long-wave travel time than given by $T_{d}$ as given by Eq. (6).

\section{Withdrawal from a side outlet}

We now consider the fixed lateral outflow, started at time $T_{w}$. This causes a decrease of the water level $Y$ in the canal, unless it is controlled (constant $Y$ ). This decrease appears when the flow is uniform, or when the water level is controlled by a fixed structure (gate or weir).

In order to estimate the downstream discharge $Q_{d}{ }^{(w)}$, the dynamics of $Y$ due to the withdrawal need to be determined. Since the use of the complete linearized Saint-Venant's equations leads to rather complex calculations, it is preferable to use simpler methods such as 
Integrator Delay (ID) method (Schuurmans et al., 1999), or Integrator Delay-Zero (IDZ) model (Litrico \& Fromion, 2004). Compared to the ID model, IDZ accounts better for short waves, which cause the drop of the water level as soon as the lateral outlet is opened. Fields tests are presented in several papers (see review in Clemmens et al., 2012). Using the IDZ approximation, the response $q_{d}^{(w)}=Q_{d}{ }^{(w)}-Q_{0}$ to a local discharge withdrawal $q_{w 0}$ is given by

- for $t<T_{w}$ :

$$
q_{d}^{(w)}(t)=q_{d, 0}=0
$$

- for $t \geq T_{w}$ :

$$
q_{d}^{(w)}(t)=-q_{w 0}\left(1-\frac{e^{-\left(t-T_{w}\right) / K_{p}}}{1+k_{d} a}\right)
$$

where $a\left[\mathrm{in} \mathrm{m} /\left(\mathrm{m}^{3} / \mathrm{s}\right)\right]$ is the instantaneous level decrease response to a discharge withdrawal, and $K_{p}$ is the time constant of the pool associated with outlet flow changes. This differs slightly from $K$ which is the pool time constant associated with upstream inflow changes. The values of $K$ and $K_{p}$ are similar in magnitude and both are influenced by the downstream boundary conditions. Calculation details are reported in the appendix. The water level variation is

$$
y(t)=q_{d}^{(w)}(t) / k_{d}
$$

Parameters $a$ and $K_{p}$ can easily be determined from a simple step response test.

\section{Coupling the step inflow to the step withdrawal}

\section{Case of a fixed withdrawal}

The case of a fixed outlet flow, such as the one imposed by a pump, combined with a gravity structure for the continuing canal downstream is considered first.The linear framework allows both responses to besuperimposed. The intent is to find the time when the volume delivered downstream is not influenced by the combination of upstream flow change and outlet flow 
change. Because of the gradual arrival of the discharge from upstream, the outlet can not be opened when the flow first arrives. Instead, the flow must increase for some time, during which extra flow will pass downstream. After the outlet is opened (at time $T_{w}$ ), the flow downstream should be lower than the reference flow until the full amount of the upstream flow change arrives. The intent then is to balance these deviations in volume.

In the case where the opening occurs after the short waves arrive, say $T_{w}>\tau$, the response $q_{d}(t)$ is given by:

- for $t<\tau$ :

$$
q_{d}(t)=q_{d, 0}=0
$$

- for $\tau<t<T_{w}$ :

$$
q_{d}(t)=\left(1-\mathrm{e}^{-(t-\tau) / K}\right) \delta Q_{u}
$$

- for $t>T_{w}$ :

$$
q_{d}(t)=\left(1-\mathrm{e}^{-(t-\tau) / K}\right) \delta Q_{u}-\left(1-\frac{\mathrm{e}^{-\left(t-T_{w}\right) / K p}}{1+k_{d} a}\right) q_{w 0}
$$

Since the released discharge should be equal to the withdrawn discharge, $q_{w 0}$ can replace $\delta Q_{u}$ in Eq. (12a), leading to

$$
q_{d}(t)=q_{w 0}\left(\frac{\mathrm{e}^{-\left(t-T_{w}\right) / K p}}{1+k_{d} a}-\mathrm{e}^{-(t-\tau) / K}\right)
$$

As in Eqs. (5) and (9), $y(t)=q_{d}(t) / k_{d}$. The volume $I$ flowing in the canal downstream of the outlet is obtained by integration of Eqs. (10-12). After a change of variable to remove the delay $\tau$, wheret $t_{w}=T_{w}-\tau$, we get :

$$
I=q_{w 0}\left(\left[t+K \mathrm{e}^{-t / K}\right]_{0}^{t_{w}}+\left[K \mathrm{e}^{-t / K}-K_{p} \frac{\mathrm{e}^{-\left(t-t_{w}\right) / K p}}{1+k_{d} a}\right]_{t_{w}}^{+\infty}\right)
$$

When this volume is zero $(I=0)$, the increase in volume passed downstream before the offtake is opened matches the decrease in volume downstream after the offtake is opened. The time $t_{w}$ for which $I=0$ isthe solution of

$$
\left(t_{w}+K \mathrm{e}^{-t_{w} / K}-K\right)+\left(0-K \mathrm{e}^{-t_{w} / K}+\frac{K_{p}}{1+k_{d} a}\right)=0
$$


Author-produced version of the article published in Journal of Irrigation and Drainage Engineering-Asce, 2013, N ${ }^{\circ} 139(4)$, p. 300-308

The solution to Eq. (14)gives the time $t_{w}$ to switch the offtake pump on, namely :

$$
t_{w}=K-\frac{K_{p}}{1+k_{d} a}
$$

This means that the time at which to change the offtake flow to provide volume compensation depends on the way the downstream level is controlled by the cross-structure (here represented by the coefficient $k_{d}$ ). Indeed, if the downstream level is perfectly controlled, i.e. if $k_{d} \rightarrow \infty$, we get :

$$
T_{w}=\tau+K
$$

If the canal is ended by an effective water level control structure (hydromechanical gate, duckbill weir, automatic weir or gate), Eq. (11) shows that the pump should therefore be switched on when the downstream flow reaches $1-1 / e \approx 63 \%$ of the total flow reponse time, since $t-\tau=K$. As previously shown, this time corresponds to the travel time of long waves. It is also equal to the dynamic storage time $T_{v}$.

This solution also applies to the case where the offtake is gravity fed, and an increase in discharge is passed downstream through a structure which provides constant flow. This would maintain the correct volume to the offtake structure.

\section{Case of a gravity outlet and gravity check structure}

Consider the case where the flow through the outlet $Q_{w}$ is influenced by the water level $y$. A typical gravity outlet is a vertical sluice gate for which the discharge and water depth are related by a standard gate discharge equation :

$$
Q_{w}=C_{c} B_{w} W_{w} \sqrt{2 g\left(Y-y_{w}-C_{c} W_{w}\right)}
$$

where $B_{w}$ is the gate width, $W_{w}$ its opening, $y_{w}$ its crest elevation and $C_{C}$ the contraction coefficient (close to 0.6). When the water level $Y$ is above the design level $Y_{0}, Q_{w}$ is greater than the design discharge $q_{w 0}$. The linear approach gives an estimate of this deviation. Introducing $k_{w}=\partial Q_{w} / \partial y$, the first order approximation gives

$$
Q_{w} \approx q_{w 0}+k_{w} y
$$


Author-produced version of the article published in Journal of Irrigation and Drainage Engineering-Asce, 2013, N ${ }^{\circ} 139(4)$, p. 300-308 The original publication is available at http://ascelibrary.org

Doi: $10.1061 /($ asce)ir.1943-4774.0000545

with

$$
k_{w}=\frac{C_{c} B_{w} W_{w} \sqrt{2 g}}{2 \sqrt{Y_{0}-y_{W}-C_{c} W_{w}}}
$$

This is valid provided water level variations $y$ are small compared to the head on the outlet. Compared to the non-gravity outlet, there is an extra volume flowing through the outlet, due to gravity, as long as $y>0$, but the flow is reduced when $y<0$. Therefore, the time of opening may be changed. We denote $T_{w}$ ' this time, and $t_{w}{ }^{\prime}=T_{w}{ }^{\prime}-\tau$. When $t>T_{w}$ ', the coupling between the water level and the discharge at the downstream end of the pool will be different from that for a fixed withdrawal, and then the transfer functions may also be changed. We denote $K$ ' and $K_{p}$ ' the time constants observed when the second gravity structure is opened. The pool delay, denoted $\tau$ ', must also be changed in order to assure the continuity of discharge at $t=T_{w}$ ' with Eq. (11). This implies that $\tau^{\prime}-\tau=\left(1-K^{\prime} / K\right) t_{w}$ '. The volume $I^{\prime}$ passing downstream is obtained by modifying Eq. (13) as follows:

$$
I^{\prime}=q_{w 0}\left(\left[t+K e^{-\frac{t}{K}}\right]_{0}^{t_{w}^{\prime}}+\left[K^{\prime} e^{-\frac{t+\tau-\tau \prime}{K^{\prime}}}-\frac{K_{p}{ }^{-} e^{-\frac{t-t_{w}^{\prime}}{K p^{\prime}}}}{1+\left(k_{d}+k_{w}\right) a}\right]_{t_{w}^{\prime}}^{+\infty}\right)
$$

To find the time $t_{w}$ ' that assures volume compensation $\left(I^{\prime}=0\right)$, an estimation of $K^{\prime}$ and $K_{p}$ ' is needed. To do that, we consider the case where gravity effects are significant, say $k_{d}$ are $k_{w}$ are small, which means $1+\mathrm{a} k_{d} \approx 1$ and $1+a k_{w} \approx 1$. From the definition of $K_{p}$ (see appendix), we find that $K_{p}^{\prime}=\frac{k_{d}}{k_{d}+k_{w}} K_{p}$. Similarly, we would have $K^{\prime}=\frac{k_{d}}{k_{d}+k_{w}} K$. Setting $\gamma=k_{w} / k_{d}$ and after a few calculatory manipulations, $I^{\prime}=0$ yields

$$
t_{w}^{\prime}-K+\frac{\gamma K}{1+\gamma} e^{-\frac{t_{w}^{\prime}}{K}}+\frac{1}{1+\gamma} \frac{K_{p}}{1+k_{d} a}=0
$$

Unlike in the non-gravity case, this equation does not give explicitly the optimal time $t_{w}$ ',due to the exponential term. A reasonable assumption is to consider that $t_{w}$ ' is close to $t_{w}$, namely $\Delta t_{w}=t_{w}{ }^{\prime}-t_{w}$ is small compared to the pool time constant $K$. The Taylor series development of $\mathrm{e}^{-\frac{t_{w^{\prime}}}{K}}$ up to the first order of $\Delta t_{w} / K$ gives

$$
t_{w}+\Delta t_{w}-K+\frac{\gamma K}{1+\gamma} \mathrm{e}^{-\frac{t_{w}}{K}}\left(1-\frac{\Delta t_{w}}{K}\right) K+\frac{1}{1+\gamma} \frac{K_{p}}{1+k_{d} a} \approx 0
$$


Author-produced version of the article published in Journal of Irrigation and Drainage Engineering-Asce, 2013, N ${ }^{\circ} 139(4)$, p. 300-308 The original publication is available at http://ascelibrary.org

Doi: 10.1061/(asce)ir.1943-4774.0000545

Using Eq. (15) and rearranging, one obtains

$$
\Delta t_{w} \approx \gamma \frac{K-t_{w}-K \mathrm{e}^{-\frac{t_{w}}{K}}}{1+\gamma\left(1-\mathrm{e}^{-\frac{t_{w}}{K}}\right)}
$$

Considering that $t_{w} / K$ is lower than 1 , the Taylor series development up to the first order of $t_{w} / K$ gives

$$
\frac{\Delta t_{w}}{t_{w}} \approx-\gamma \frac{t_{w}}{2 K}
$$

This proves that, when $\gamma=k_{w} / k_{d}$ is small(e.g., when the outlet is small relative to the continuing canal), the optimal time should be changed by only a small value compared to the constant flow withdrawal. A development up to the second order of Eq. (19) slightly improves the approximation of $\Delta t_{w}$, giving

$$
\begin{gathered}
\Delta t_{w} \approx \frac{-(1+\gamma \varepsilon)+\sqrt{(1+\gamma \varepsilon)^{2}-2 \gamma^{2}(1-\varepsilon)\left(\frac{t_{w}}{K}-\varepsilon\right)}}{\gamma(1-\varepsilon)} K \\
\text { in which } \varepsilon=1-\mathrm{e}^{-\frac{t_{w}}{K}}
\end{gathered}
$$

\section{APPlicAtion TESTS}

\section{General}

The configuration described in Fig. 1 is simulated using the linear approach described above, and a full Saint-Venant's equations solution is provided as a reference. The simulations are performed with SIC, which solves the standard energy equation in steady flow, and the full Saint-Venant equations using a Preissmann scheme for unsteady flow (Baume et al. 2005). In the first step, the parameters of the elementary transfer functions (transfer of a flow release $q_{u}$ to the downstream flow $q_{d}^{(r)}$, transfer of a side withdrawal $q_{w}$ to the downstream flow $\left.q_{d}{ }^{(w)}\right)$ are identified by fitting the linear model of the simulated downstream discharge in response to a flow release, then to a withdrawal at the outlet. Then, both operations are combined with different times of opening $T_{w}$, and volume compensation is analyzed at the downstream end. The opening time which ensures volume compensation is finally determined 
Author-produced version of the article published in Journal of Irrigation and Drainage Engineering-Asce, 2013, N ${ }^{\circ} 139(4)$, p. 300-308 The original publication is available at http://ascelibrary.org

Doi: 10.1061/(asce)ir.1943-4774.0000545

by both linear and nonlinear methods. Practical applications are presented in the discussion section.

\section{Canal parameters}

The tests were conducted with a rectangular open-channel, of width $b=2 \mathrm{~m}$, bed slope $S_{f}=$ $4.4 \times 10^{-4}$ and Manning coefficient $n=0.014 \mathrm{~s} / \mathrm{m}^{1 / 3}$. The length of the pool is $L=2300 \mathrm{~m}$. An outlet is located at $x=2290 \mathrm{~m}$ downstream from the upstream gate. We will consider the different situations described in Fig. 1: the uniform flow condition (normal depth $Y_{n}$ ), and the canal ended by a control structure such as a gate or a weir, at $x=2300 \mathrm{~m}$. In the case of the uniform flow, the canal is made twice as long $(4600 \mathrm{~m})$ in order to be able to capture the hysteresis of the stage-discharge relationship in unsteady flow, but the response (discharge $Q_{d}$ ) is still observed at $x=2300 \mathrm{~m}$. The simulation time step is 1 minute. Step variations (at head or at the outlet) are made over one time step.

The initial discharge is $Q_{0}=1.9 \mathrm{~m}^{3} / \mathrm{s}$, while the design discharge of the outlet is $q_{w 0}=0.19 \mathrm{~m}^{3} / \mathrm{s}$. The control structures (weir or gate) impose a downstream depth $Y_{0}=1.235 \mathrm{~m}$, while the normal depth is $Y_{n}=1 \mathrm{~m}$. Both the weir and the gate have a fixed position during the simulations. The weir is long-crested so as to ensure a constant water level (level variation limited to $0.01 \mathrm{~m}$ for $10 \%$ discharge variation). It is representative of the typical situation where water level is controlled whether by a long-crested weir or a by an automatic gate. We also simulated a perfect constant level (level variation lower than $0.001 \mathrm{~m}$ for $10 \%$ discharge variation). The canal response to a step inflow is very close to the one obtained with the longcrested weir. For the step withdrawal, parameters $a$ and $K_{p}$ are not sensitive due to the infinite $k_{d}$. In the following, the situation where downstream water level is maintained constant will be simulated with the long-crested weir. The case of the fixed gate is typical of manually operated systems; with the selected dimensions, a discharge increase by $10 \%$ causes a rise of $0.25 \mathrm{~m}$.

The parameters of the transfer functions are first identified by performing two elementary operations : 
- a flow release of $\delta Q_{u}=0.19 \mathrm{~m}^{3} / \mathrm{s}$, at the upstream end of the canal after a steady flow period (discharge $\left.Q_{0}\right)$;

- a step withdrawal of $q_{w 0}=\delta Q_{u}$ after a steady flow period (discharge $Q_{0}$ ).

Both operations are performed at time $t_{0}=60 \mathrm{~min}$ with SIC (referred to as Saint-Venant's model) and with the linear models (Eqs. 3-5 for the step release, Eqs. 7-9 for the step withdrawal). From the simulated flow release, parameters $\tau, K$ and $k_{d}$ of the linear model (Eqs. 4-5) are identified. The linear model can be perfectly fitted with Saint-Venant's results (Figs. 2a, 2c). In the case where a control structure is present (gate or weir), there is also a very good correspondence between predicted and observed water levels, which justifies the linear approximation of the downstream coupling (Eq. 2). In the case of uniform flow, the comparison is not as good, since the transcient stage-discharge relationship may be nonunique and depend on the local depth gradient. Yet, this effect has a limited influence.

$<$ Figure 2 about here $>$

The step withdrawal leads to the determination of parameters $a$ and $K_{p}$ of IDZ linear model (Eqs. 8-9). The linear model also gives a response very close to Saint-Venant's model (Figs 2b, 2d). In uniform flow, a similar deviation as for the step release is observed. Model parameters are summarized in Table 1 . The speed of the diffusive wave and the propogation time $T_{d}$ can be computed using Eq. (6). We obtain $T_{d}=L / c_{d} \approx 30.4$ minutes, which is very close to the value of $T=\tau+K \simeq 29.3$ minutes obtained by identification on the step response for the uniform flow.The dynamic storage time $T_{V}$ is obtained by making the difference of volumes between the steady flows at $Q_{0}$ and $Q_{0}+\delta Q_{u}$, keeping the water level constant at the set point $Y_{0}$, and then dividing this difference by $\delta Q_{u}$. The result is 18.2 minutes. This essentially matches the travel time of long waves in the canal perfectly controlled, $T=\tau+K \simeq 18.1 \mathrm{~min}$, obtained by identification on the step response. The previous works by Bautista et al. (2003, 2005) explained that the volume compensation delay is bounded by the travel time of short waves and the travel time of the kinematic wave, which are both calculated simply from the uniform flow characteristics $\left(L / C_{s w} \approx 9\right.$ min and $\left.L / C_{d} \approx 30 \mathrm{~min}\right)$. 


\section{Time of opening and volume compensation}

Aflow release at the head is considered at $t_{0}=60 \mathrm{~min}$. A constant withdrawal is made at $t=t_{0}+T_{w}$. From Eq. (15), an estimation of the optimal time can be determined which ensures volume compensation. The corresponding values are given in Table 2. For the three situations, different times are expected, since the canal and the pool transfer functions are very different. Notice however that the optimal times are close to each others. They are also close to $T_{v}$, and smaller than $T_{d}$.

The corresponding simulations are made with both linear (Eqs. 10-12) and Saint-Venant models, at 20, 18 and 17 minutes for downstream boundaries defined by uniform flow, the weir, and the gate respectively. Results are shown in Fig. 3.

$<$ Figure 3 about here $>$

Note that the Saint-Venant response (downstream discharge $Q_{d}$ ) is very well approximated by the linear model, obtained by superposition of the linear response to the step release and the step withdrawal (Eqs. 10-12). The simulation with the gate gives larger errors during a short transcient period just after the outlet is opened (up to $0.01 \mathrm{~m}^{3} / \mathrm{s}$ ). This deviation is explained by nonlinearities in the pool response, as the pool constant $K_{p}$ slightly depends on the initial state. This error results from a deviation $I$ of the volumepassing downtream, calculated by the Saint-Venant model, which is $-12.5 \mathrm{~m}^{3}$. This corresponds to an outlet flow for a bit more than 1 minute, and thus the opening should be delayed by this time. This error is rather small, about $6 \%$, compared to $T_{w}$. The volume deviation is smaller for the uniform flow $\left(-4.1 \mathrm{~m}^{3}\right.$, i.e. flow change for $22 \mathrm{~s})$ and for the weir $\left(-1.5 \mathrm{~m}^{3}\right.$, i.e. flow change for $\left.8 \mathrm{~s}\right)$. The downstream volume deviation can be plotted as a function ofthe opening time(Fig. 4). This figure confirms that the linear approach gives a very good approximation of $I$, and that it can be used to determine the volume compensation time. 
By performing a series of calculations with different withdrawal times, one can calculate this time with the Saint-Venant model by trial and error. The values, reported in Table 2, are close to those obtained from Eq. (15).Note that the weir and the gate give similar values for $T_{w}$, although the canal dynamics are very different.

The discharge increase in the canal can be determined at the time when it is the most suitable to open the outlet. Since attenuation is low for the canal ended by the weir, the discharge increased by $0.111 \mathrm{~m}^{3} / \mathrm{s}$ before the outlet was opened, in response to the upstream release. This corresponds to a proportion $\alpha=59 \%$ of $\delta Q_{u}$, close to the $63 \%$ that would be obtained with a perfect level control. After the outlet is opened, the discharge drops $0.042 \mathrm{~m}^{3} / \mathrm{s}$ below the reference discharge, and then increases during about 1 hour, until it reaches the reference discharge. The volume deviations before and after the outlet opening are then balanced. The proportion $\alpha$ is smaller with the uniform flow ( $44 \%$, corresponding to $0.084 \mathrm{~m}^{3} / \mathrm{s}$ ) and much smaller for the gate $\left(18 \%, 0.034 \mathrm{~m}^{3} / \mathrm{s}\right)$. In the case of the gate, the deviation from the reference discharge after the opening is rather limited $\left(-0.005 \mathrm{~m}^{3} / \mathrm{s}\right)$, but it takes a longer time to reach equilibrium.

These results suggest that the optimal time $T_{w}$ to open the outlet does not correspond to a fixed proportion of the response time for a discharge increase due to the step release. This proportion, denoted $\alpha$, is equal to $q_{d}\left(T_{w}\right) / \delta Q_{u}$, where $q_{d}\left(T_{w}\right)$ can be obtained by replacing the value of $T_{w}$ (Eq. 15) in Eq. (11). This yields

$$
\alpha=1-e^{-1+\frac{K p}{K\left(1+a k_{d}\right)}}
$$

$\mathrm{Ask}_{d} \rightarrow+\infty$, Eq (22) shows that $\alpha \rightarrow 1-1 / e=63 \%$.

$<$ Table 2 about here $>$

$<$ Figure 4 about here $>$ 


\section{DISCUSSION}

\section{Regarding the definition of the response time}

These results suggest an improved definition of the response time, based on the compensation volume.

Different response times are used in practice, such as the travel time of the diffusive wave (long waves), the dynamic storage time, the travel time of the gravity waves (short-waves), the time of maximum flow increase. The principle of volume compensation gives a more precise definition. It leads to improved distribution efficiency as it specifies that the whole released volume is given to the targeted outlet.

\section{Effect of the boundary condition}

The downstream boundary condition largely affects the canal response. In the case of uniform flow, the diffusive wave celerity is easily calculated. However, these results show that opening the outlet at the travel time of the diffusive wave does not ensure volume compensation, and that a part of the upstream flow release is lost downstream. In our example, the diffusive wave propagation time was 30min, whereas the optimal time of opening would be about 20min.

Due to feedback effects, the canal response may be accelerated in the case of a constant water level structure (long-crested weir, automated check gate, hydromechanical gate). In this case, and provided the withdrawn discharge is exactly equal to the discharge release at thehead, opening the outlet at the dynamic storage time is proved to ensure volume compensation. The optimal time of opening corresponds to $63 \%$ of the total discharge response time. This time is also the propagation time of long waves (diffusive wave), but it cannot be calculated from uniform flow conditions, as it is largely affected by the feedback of the control structure.

With a fixed check gate, the response is slower than fora constant flow structure. As in uniform flow, the optimal opening time (20 min) is largely lower than the propagation time of 
Author-produced version of the article published in Journal of Irrigation and Drainage Engineering-Asce, 2013, N ${ }^{\circ} 139(4)$, p. 300-308 The original publication is available at http://ascelibrary.org

Doi: 10.1061/(asce)ir.1943-4774.0000545

long waves $(61 \mathrm{~min})$. Opening the outlet at $T_{w}=60 \mathrm{~min}$ leads to an excess of $480 \mathrm{~m}^{3}$ downstream. The optimal time is close to the one obtained with the long-crested weir.

\section{Sensitivity to changes in canal parameters}

\section{Reference regime}

Canal and pool parameters were identified for given reference discharge and water level. When the same parameters are used for different regimes, the linear approach may lead to errors due to nonlinear effects. For example, the delay should increase as the initial discharge decreases, and conversely. This effect is analyzed with the canal ended by the weir. The canal response is simulated for initial discharges $Q_{0}=0.5,1.2,1.9$, and $2.6 \mathrm{~m}^{3} / \mathrm{s}$. Figure 5 shows that the linear response remains very close to the complete Saint-Venant's solution. The maximum deviation is for the lowest discharge, but this deviation remains limited.

In practice, it is preferable to use tabulated values of the canal parameters $\left(K, \tau, a, K_{p}\right)$, depending on the regime, so that the linear response remains very accurate. In our example, the parameters obtained with $Q_{0}=1.9 \mathrm{~m}^{3} / \mathrm{s}$ apply very well from $Q_{0}=1.2 \mathrm{~m}^{3} / \mathrm{s}$ to $Q_{0}=2.6 \mathrm{~m}^{3} / \mathrm{s}$. The response for $Q_{0}=0.5 \mathrm{~m}^{3} / \mathrm{s}$ remains acceptable. Indeed, the flow dynamics is mainly controlled by the short wave celerity $C_{s w}$, largely greater than the mean flow velocity,and by the storage of the pool. Since the downstream water level is controlled, both characteristics are little changed when the discharge is changed. Figure5shows that the response is slightly delayed in the case of $Q_{0}=0.5 \mathrm{~m}^{3} / \mathrm{s}$, due to a decrease of the water depth in the upstream part of the pool (and then a decrease of the short wave celerity), and a moderate decrease of the flow velocity. With the same parameters as for $Q_{0}=1.9 \mathrm{~m}^{3} / \mathrm{s}$, an excess of $8.3 \mathrm{~m}^{3}$ results, which means that the outlet should be opened 44 s later in order to ensure volume compensation. This delay remains limited, although it can be addressed using the canal parameters for the corresponding regime. 
Author-produced version of the article published in Journal of Irrigation and Drainage Engineering-Asce, 2013, N ${ }^{\circ} 139(4)$, p. 300-308 The original publication is available at http://ascelibrary.org

Doi: 10.1061/(asce)ir.1943-4774.0000545

\section{Change in canal roughness}

Similarly, we simulated changes in friction by increasing Manning roughness coefficient by $10 \%, 25 \%, 50 \%$ and $100 \%$. This corresponds to the situation where the canal parameters given in Table 1 were obtained when the canal was clean, and then flow changes are applied later when vegetation has developed on the canal banks (e.g., Lozano et al., 2012). The simulated flow changes are presented in Fig. 5. We can see that a reasonable change in roughness causes a limited effect on flow propagation. Increasing the roughness decreases the flow velocity (mainly in the uniform part), but it also increases the water level, and then the celerity of the surface waves. This implies that the arrival of the flow release is almost unchanged. Howerer, the filling of the pool is largely delayed when roughness is very large.With $n=0.0154 \mathrm{~s} / \mathrm{m}^{1 / 3}$, which is a significant roughness change $(+10 \%), T_{w}$ should be delayed by about 1 minute to ensure volume compensation. It is almost 4 minutes for $n+25 \%$. In practice, the use of tabulated values for canal parameters is a way to address situations when roughness largely varies throughout the year.

$<$ Figure 5 about here $>$

\section{Gravitational outlets}

In the case of a gravitational outlet, the outlet is opened at a fixed opening. Therefore, its discharge is not constant, as it increases if the water level in the pool increases. Consider a side outlet consisting of a gate of width $B_{w}=0.4 \mathrm{~m}$, crest elevation $y_{w}=0.3 \mathrm{~m}$ and $C_{C}=0.6$. The withdrawal is performed at different times $\left(t_{0}+19,30\right.$ and $\left.60 \mathrm{~min}\right)$ by opening the outlet to a fixed position $\left(W_{w}=0.198 \mathrm{~m}\right)$, which ensures a withdrawal of $q_{w 0}=0.190 \mathrm{~m}^{3} / \mathrm{s}$ for the design water level $Y_{0}$. Equation (18) gives $k_{w} \simeq 0.108 \mathrm{~m}^{2} / \mathrm{s}$. This value is much smaller than $k_{d}$, which implies that the downstream discharge should be close to the one obtained with the fixed discharge (Eqs. 10-12). The linear approximation of the side discharge, obtained from Eq. (17),causes an error lower than $1 \%$ in the range $Y \in\left[Y_{0}-0.12 \mathrm{~m} ; Y_{0}+0.49 \mathrm{~m}\right]$, which is a large range. 
With a perfect downstream level control, gravity has no effect on $Q_{w}$. Simulation was performed with the canal ended by a fixed gate with an upstream flow release at $t_{0}=60 \mathrm{~min}$, followed by a step withdrawal obtained with a fixed opening. Figure 6compares the linear simulation with the complete Saint Venant's solution for three opening times $\left(t_{0}+17,30\right.$ and 60min). Note that both approaches give reasonable trends. The linear approach generally overestimates the Saint Venant's solution. This is due to the fact that the lateral outlet slightly changes the feedback, and then the parameters of the transfer functions (see appendix). The overestimation is rather limited (less than $1 \mathrm{l} / \mathrm{s}$ ), which confirms the validity of the linear assumption.

The gravitational effects may lead to overestimation of the withdrawn discharge if the outlet is opened after the optimal time. The overestimation is higher for the gate and the latest opening ( $T_{w}=60 \mathrm{~min}$ ), since the water level reaches $13 \mathrm{~cm}$ above its design value. This leads to an overestimation of about $35 \mathrm{~m}^{3}$ compared to the fixed withdrawal. If the outlet is opened at the optimal time (here, $t_{0}+17 \mathrm{~min}$ ), there is almost no impact on the volume. Indeed, after the flow has arrived anduntil the outlet is opened, the water level is above its reference value. When the outlet is opened, its takes more than its design discharge and the water level drops more than what it would do if we had $q_{w}=q_{w 0}$. This, in turn, implies that $q_{w}$ becomes lower than $q_{w 0}$.Then, the excess of withdrawn flow (immediately after the opening) is compensated by the negative deviation that appears later. This implies that the optimal opening time is almost unchanged compared to the fixed withdrawal.Equation (20) shows that one should anticipate the opening by about $\Delta t_{w} \approx 0.16 \mathrm{~min}$, which can be neglected.

The extreme case is when both structures (inline and outlet) are of the same size. In this case, $k_{d}=k_{w}$ and they will take the same discharge. Equation (20) gives $\Delta t_{w} \approx 1 \mathrm{~min}$, which remains small. Figure 6b shows the simulated discharges $Q_{d}$ and $Q_{w}$ with Saint-Venant model, as well as the linear response, for $T_{w}=17 \mathrm{~min}$ (obtained from Eq. 15) and $Q_{w 0}=1.9 \mathrm{~m}^{3} / \mathrm{s}$. We can see that the excess of flow $\left(Q_{w}>Q_{w 0}\right)$ when $T_{w}<t<82 \mathrm{~min}$ is compensated by the deficit $\left(Q_{w}>Q_{w 0}\right)$ when $t>82 \mathrm{~min}$, ensuring volume compensation. By trial and error, we find that the optimal time is between 16 and 17 min. The linear model still presents the same error as in Fig. 3c, but 
the optimal time for volume compensation is correctly estimated even without correction due to gravity.

$<$ Figure 6 about here $>$

\section{CONCLUSION}

Considering the existence of various definitions for the response time of an irrigation canal, a clear definition of this timehas been proposed based on the concept of volume compensation,considering the time when areleased volume is exactly passed through a downstreamoutlet.

Based on linear theory, a method has been proposed to calculate this response time analytically from the canal characteristics. These characteristics may be obtained theoretically from physical parameters, including those of the downstream control structure, or, more practically, from simple analyses of canal response.

One shows that, when the downstream level is perfectly controlled, the time which ensures volume compensation is the one when the discharge increase has reached $63 \%$ of its final value. This corresponds to the dynamic storage time. This resultdoes not apply when the downstream level is not perfectly controlled, which is the case for a fixed gate or a uniform flow.

\section{REFERENCES}

Ankum, P. 1995. Flow Control in Irrigation and Drainage. Report No. 65, Water Management Department, Delft University of Technology. The Netherlands.

Baume, JP, Malaterre, PO, Belaud, G., \& Le Guennec, B. 2005. "SIC: a 1D HydrodynamicModelforRiverandIrrigation Canal ModelingandRegulation", in Métodos Numéricos em Recursos Hidricos 7, ABRH (AssociacaoBrasileira de Recursos Hidricos), CoppetecFundacao, Ed. R.C. Vieira da Silva, pp 1-81, ISBN 85-88686-14-7

Bautista, E., Strelkoff, T.S., \& Clemmens, A.J. 2003. General characteristics of solutions to the open-channel flow, feedforward control problem. Journal of Irrigation and Drainage Engineering, 129(2), 129-137. 
Author-produced version of the article published in Journal of Irrigation and Drainage Engineering-Asce, 2013, N¹39(4), p. 300-308 The original publication is available at http://ascelibrary.org

Doi: 10.1061/(asce)ir.1943-4774.0000545

Burt, C., \& Plusquellec, H. 1990. Management of far irrigation system. Water delivery control. American Society of Agricultural Engineers, St Joseph, MI. 373-423.

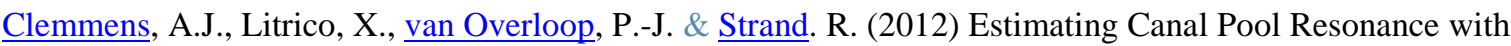
Auto Tune Variation. Journal of Irrigation and Drainage Engineering 138:1, 9-15

Litrico, X., \& Fromion, V. 2004. Simplified Modeling of Irrigation Canals for Controller Design. Journal of Irrigation and Drainage Engineering, 130(5), 373-383.

Lozano, D., Dorchies, D., Belaud, G., Litrico, X.\& Mateos, L., 2012. A simulation study on the influence of roughness on the downstream automatic control of an irrigation canal. Journal of Irrigation and Drainage Engineering, 138, 285-293

Munier, S., Belaud, G., \& Litrico, X. 2010. Closed-form Expression of the Response-Time of an Open-Channel. Journal of Irrigation and Drainage Engineering, 136, 677-684.

Schuurmans, J., Bosgra, O.H., \& Brouwer, R. 1995. Open-channel flow model approximation for controller design. Applied Mathematical Modelling, 19(9), 525-530.

Schuurmans, W. 1990. Analytical formulae for the response time of irrigation canals. Irrigation and Drainage Systems, 4(1), 37-58.

Schuurmans, J., Clemmens, A., Dijkstra, S., Hof, A., \& Brouwer, R. (1999). Modeling of Irrigation and Drainage Canals for Controller Design. Journal of Irrigation and Drainage Engineering, 125(6), 338-344.

Strelkoff, T. S., Deltour, J. L., Burt, C. M., Clemmens, A. J., \& Baume, J. P. 1998. Influence of Canal Geometry and Dynamics on Controllability. Journal of Irrigation and Drainage Engineering., 124(1), 16-22.

\section{APPENDiX. TRANSFER FUnCTIONS}

Following the approach developed in Litrico and Fromion (2004), the Saint-Venant transfer matrix between water level variations $\left(y_{0}, y_{1}\right)$ and discharge variations $\left(q_{0}, q_{1}\right)$ is written, where 0 denotes the upstream end of the canal, 1 denotes the downstream end:

$$
\left[\begin{array}{l}
\hat{y}_{0} \\
\hat{y}_{1}
\end{array}\right]=\left[\begin{array}{ll}
p_{11} & p_{12} \\
p_{21} & p_{22}
\end{array}\right] \cdot\left[\begin{array}{l}
\hat{q}_{0} \\
\hat{q}_{1}
\end{array}\right]
$$

where $\hat{f}$ denotes the Laplace transform of function $f$, and all functions depend on Laplace variable $s$. At the downstream end, the discharge outflow $q_{1}$ is the sum of the discharges $q_{d}$ (passing downstream) and the withdrawn discharge $q_{w}$. Using Eq. (A1) and the linear coupling at the downstream structure (Eq. 5), one has

$$
\hat{q}_{d}=\frac{k_{d} p_{21}}{1-k_{d} p_{22}} \hat{q}_{0}+\frac{k_{d} p_{22}}{1-k_{d} p_{22}} \hat{q}_{w}
$$


The right-hand term is composed of two parts: one for the transfer of the upstream discharge release, and one for the transfer of the withdrawal. Now we use analytical approximations of these transfer functions. Munier et al. (2010) have shown that the first transfer function can be approximated by a first-order with delay model:

$$
\frac{k_{d} p_{21}}{1-k_{d} p_{22}} \approx \frac{e^{-\tau s}}{1+K s}
$$

The second transfer function can be approximated by a similar dynamics, but without delay since the withdrawal and the downstream discharge are considered at the same location. The IDZ model (Litrico and Fromion, 2004) gives a more accurate description of the pool dynamics:

$$
p_{22}(s)=-a-\frac{b}{s}
$$

Parameters $a$ and bare linked to the pool characteristics: $a$ is the instantaneous level decrease response to a discharge withdrawal, which represents the high-frequency response of the pool, and $b$ is the inverse of the backwater area. The transfer function of the side withdrawal is then simplified as follows:

$$
\frac{k_{d} p_{22}}{1-k_{d} p_{22}} \approx-1+\frac{s}{\left(1+k_{d} a\right) s+k_{d} b}
$$

Setting $K_{p}=\frac{1+k_{d} a}{k_{d} b}$, the above expression is re-written as

$$
\frac{k_{d} p_{22}}{1-k_{d} p_{22}} \approx-1+\frac{1}{\left(1+k_{d} a\right)} \cdot \frac{K_{p} s}{1+K_{p} s}
$$

In the time domain, the response to a step withdrawal $q_{w 0}$ at $T_{w}$ is given by Eq. (8).

for a gravity outlet, Eq. (24) will be modified by replacing the side discharge $\hat{q}_{w}$ (step withdrawal) by $\hat{q}_{w}{ }^{\prime}=$ $\hat{q}_{w}+k_{w} \hat{y}_{d}$. The downstream response is obtained as follows:

$$
\widehat{q}_{d}^{\prime}=\frac{k_{d} p_{21}}{1-\left(k_{d}+k_{w}\right) p_{22}} \hat{q}_{0}+\frac{k_{d} p_{22}}{1-\left(k_{d}+k_{w}\right) p_{22}} \widehat{q}_{w}
$$

If $k_{d}>>k_{w}$, the downstream response is little affected by the gravity effect. Assuming $\widehat{q}_{d}^{\prime} \approx \hat{q}_{d}$, gives $\hat{q}_{w}{ }^{\prime} \approx \hat{q}_{w}+$ $\frac{k_{w}}{k_{d}} \hat{q}_{d}$ 


\section{List of figures}

Figure 1: Sketch of the system and notation

Figure 2: identification of canal parameters for the step release (a, c) and for the step withdrawal (b, d). First line: discharge deviations $q_{d}^{(r)}$ and $q_{d}{ }^{(w)}$; second line: water level deviation $y$.

Figure 3: Simulation of a flow release and withdrawal. (a): uniform flow; (b): flow is controlled by a long weir ; (c) : flow is controlled by a bottom sluice gate. The linear simulations correspond to Eqs. (10-12)

Figure 4: Downstream volume deviation $I$ as function of $T_{w}$

Figure 5: Simulation of a flow release at $t=60 \mathrm{~min}$, step withdrawal at $t=78 \mathrm{~min}\left(T_{w}=18 \mathrm{~min}\right)$. Downstream level is controlled by the weir. (a) Effect of varying initial discharge. Initial discharge : 0.50, 1.20, 1.90, 2.6m³ $/ \mathrm{s}$. The parameters of the linear model are those calibrated for $Q_{0}=1.9 \mathrm{~m}^{3} / \mathrm{s}$. (b): Effect of varying Manning friction coefficient $(+10 \%,+25 \%,+50 \%,+100 \%)$. The parameters of the linear model are those calibrated for $n=0.014 \mathrm{~s} / \mathrm{m}^{1 / 3}$. The effect of varying friction coefficient is simulated with the full Saint-Venant's model (SV).

Figure 6: Case of gravity outlets. (a) Withdrawn discharge with a gravity outlet, with the gate as downstream boundary condition, design discharge $0.190 \mathrm{~m}^{3} / \mathrm{s}$. The opening is perfomed as a step at $T_{w}=t_{0}+17 \mathrm{~min}, t_{0}+30 \mathrm{~min}$, $t_{0}+60 \mathrm{~min}$. (b) Case of equal structures, design discharge $1.9 \mathrm{~m}^{3} / \mathrm{s}$.

\section{List of Tables}

Table 1: Simulation parameters for the study case

Table 2: Results for optimal time of opening, constant rate of withdrawal $\left(q_{w 0}=0.19 \mathrm{~m}^{3} / \mathrm{s}\right.$ for $\left.t>t_{0}+T_{w}\right)$ 
Author-produced version of the article published in Journal of Irrigation and Drainage Engineering-Asce, 2013, N ${ }^{\circ} 139(4)$, p. 300-308 The original publication is available at http://ascelibrary.org

Doi: $10.1061 /($ asce)ir.1943-4774.0000545

Table 1: Simulation parameters for the study case

\begin{tabular}{|lcccc|}
\hline Parameter & Uniform & Perfect control & Weir & Gate \\
\hline Downstream depth $Y_{0}(\mathrm{~m})$ & $\begin{array}{c}1.01 \\
\text { unif. flow } \\
\text { (imposed at } \\
x=4600 \mathrm{~m})\end{array}$ & 1.235 & 1.235 & 1.235 \\
length=20m & $\begin{array}{c}\text { width=2m } \\
\text { Opening } \\
\text { Canal transfer function }\end{array}$ & & & $=0.356 \mathrm{~m}$ \\
Feedback coef. $k_{d}\left(\mathrm{~m}^{2} / \mathrm{s}\right)$ & 2.5 & $+\infty$ & 21.0 & 0.9 \\
Delay time $\tau$ (min) & 6.5 & 7.0 & 7.2 & 6.4 \\
Canal time constant $K(\mathrm{~min})$ & 22.8 & 11.1 & 12.2 & 54.4 \\
\hline Pool reaction to a withdrawal & & & & 0.18 \\
Sensitivity $a\left(\mathrm{~s} / \mathrm{m}^{2}\right)$ & 0.77 & - & 0.21 & 50.8 \\
Pool time constant $K_{p}$ (min) & 28.3 & - & 7.9 & \\
\hline
\end{tabular}


Author-produced version of the article published in Journal of Irrigation and Drainage Engineering-Asce, 2013, N¹39(4), p. 300-308 The original publication is available at http://ascelibrary.org

Doi: $10.1061 /($ asce)ir.1943-4774.0000545

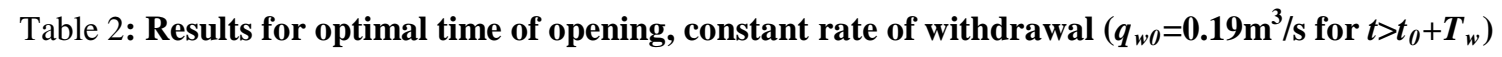

\begin{tabular}{|lccc|}
\hline Type of downstream boundary condition & Uniform & Weir & Gate \\
\hline Optimal time (linear, Eq. 15) $T_{w}$ (min) & 19.7 & 17.9 & 17.1 \\
Optimal time (Saint Venant) $T_{w}($ min) & 20.5 & 18.13 & 18.08 \\
& 0.084 & 0.111 & 0.034 \\
$\begin{array}{l}\text { Max }\left(Q_{d}-Q_{0}\right)\left(\mathrm{m}^{3} / \mathrm{s}\right) \text { (at the time when the outlet is opened) } \\
\text { Rate of total increase } \alpha\end{array}$ & $44 \%$ & $59 \%$ & $18 \%$ \\
\hline
\end{tabular}

